\title{
Performance Differences Between the Sexes in the Boston Marathon From 1972 to 2017
}

Knechtle, Beat ; Di Gangi, Stefania ; Rüst, Christoph A ; Nikolaidis, Pantelis T

\begin{abstract}
Knechtle, B, Di Gangi, S, Rüst, CA, and Nikolaidis, PT. Performance differences between the sexes in the Boston Marathon from 1972 to 2017. J Strength Cond Res XX(X): 000-000, 2018-The differences between the sexes in marathon running have been investigated for athletes competing in world class-level races. However, no information exists about changes in these differences since the first women officially began participating in marathons. We examined trends in participation and performance in the Boston Marathon from 1972 to 2017. A total of 371,250 different finishers (64\% men) and 553,890 observations-with 187,998 (34\%) being of women and 365,892 (66\%) of men-were analyzed using Generalized Additive Mixed Models. The number of finishers increased over the years. Female participation started at $2.81 \%$ in 1972 and reached $45.68 \%$ in 2016. Considering all finishers, men (03:38:42 \pm 00:41:43 h:min:s) were overall faster than women (04:03:28 \pm 00:38:32 h:min:s) by 10.7\%. Average performance worsened over the years, but the differences between the sexes decreased. For the annual 10 fastest runners, performance improved with a decrease in speed difference (18.3\% overall, men: 02:13:30 \pm 00:04:08 h:min:s vs. women: 02:37:42 \pm 00:17:58 h:min:s). For the annual winners, performance improved with a decrease in speed difference (15.5\% overall, men: 02:10:24 \pm 00:03:05 h:min:s vs. women: 02:30:43 \pm 00:11:05 h:min:s). For the near-elite finishers from the 21st to the 100th place and from the 101st to the 200th place, women's performance improved with a decrease in the difference to men. In summary, the trend in performance over the years depended on the methodological approach (i.e., all vs. annual 10 fastest finishers vs. annual winners), but the difference between the sexes decreased in all instances. Although men were $10.7 \%$ faster than women, the fastest men (i.e., top 10 and winners) increased the gap between men and women by an average of $18.3 \%$ for the annual 10 fastest and $15.5 \%$ for the annual winners.
\end{abstract}

DOI: https://doi.org/10.1519/JSC.0000000000002760

Posted at the Zurich Open Repository and Archive, University of Zurich

ZORA URL: https://doi.org/10.5167/uzh-171202

Journal Article

Published Version

Originally published at:

Knechtle, Beat; Di Gangi, Stefania; Rüst, Christoph A; Nikolaidis, Pantelis T (2020). Performance Differences Between the Sexes in the Boston Marathon From 1972 to 2017. Journal of Strength and Conditioning Research, 34(2):566-576.

DOI: https://doi.org/10.1519/JSC.0000000000002760 


\title{
Performance Differences Between the Sexes in the Boston Marathon From 1972 to 2017
}

\author{
Beat Knechtle, ${ }^{1,2}$ Stefania Di Gangi, ${ }^{\mathbf{2}}$ Christoph A. Rüst, ${ }^{2}$ and Pantelis T. Nikolaidis ${ }^{\mathbf{3}}$ \\ ${ }^{1}$ Medbase St. Gallen Am Vadianplatz, St. Gallen, Switzerland; ${ }^{2}$ Institute of Primary Care, University of Zurich, Switzerland; \\ and ${ }^{3}$ Exercise Physiology Laboratory, Nikaia, Greece
}

\begin{abstract}
Knechtle, B, Di Gangi, S, Rüst, CA, and Nikolaidis, PT. Performance differences between the sexes in the Boston Marathon from 1972 to 2017. J Strength Cond Res XX(X): 000-000, 2018-The differences between the sexes in marathon running have been investigated for athletes competing in world classlevel races. However, no information exists about changes in these differences since the first women officially began participating in marathons. We examined trends in participation and performance in the Boston Marathon from 1972 to 2017. A total of 371,250 different finishers (64\% men) and 553,890 observations-with 187,998 (34\%) being of women and $365,892(66 \%)$ of men-were analyzed using Generalized Additive Mixed Models. The number of finishers increased over the years. Female participation started at $2.81 \%$ in 1972 and reached $45.68 \%$ in 2016. Considering all finishers, men (03:38:42 \pm 00:41:43 h:min:s) were overall faster than women (04:03:28 \pm 00:38:32 h:min:s) by 10.7\%. Average performance worsened over the years, but the differences between the sexes decreased. For the annual 10 fastest runners, performance improved with a decrease in speed difference (18.3\% overall, men: 02:13:30 \pm 00:04:08 h:min:s vs. women: 02:37:42 \pm 00:17:58 h:min:s). For the annual winners, performance improved with a decrease in speed difference (15.5\% overall, men: 02:10:24 \pm 00:03:05 h:min:s vs. women: 02:30:43 \pm 00:11:05 h:min:s). For the near-elite finishers from the 21 st to the 100th place and from the 101 st to the 200th place, women's performance improved with a decrease in the difference to men. In summary, the trend in performance over the years depended on the methodological approach (i.e., all vs. annual 10 fastest finishers vs. annual winners), but the difference between the sexes decreased in
\end{abstract}

Supplemental digital content is available for this article. Direct URL citations appear in the printed text and are provided in the HTML and PDF versions of this article on the journal's Web site (http:// journals.lww.com/nsca-jscr).

Address correspondence to Beat Knechtle, beat.knechtle@hispeed.ch.

$00(00) / 1-11$

Journal of Strength and Conditioning Research

(C) 2019 National Strength and Conditioning Association all instances. Although men were $10.7 \%$ faster than women, the fastest men (i.e., top 10 and winners) increased the gap between men and women by an average of $18.3 \%$ for the annual 10 fastest and $15.5 \%$ for the annual winners.

\section{KEY WoRDS women, men, history, running}

\section{INTRODUCTION}

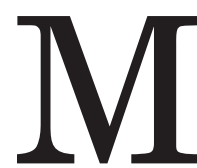

arathon running enjoys high popularity among road-based running races (7). In the United States, the number of overall finishers of marathons reached $\sim 507,600$ in 2016 ; this was slightly lower than that in 2015 with $\sim 509,000$ finishers. In these 2 years, a total of $\sim 1,100$ marathons were held (www.runningusa.org/marathon-report-2017).

In the United States, the percentage of female runners in all road-based running races increased from $\sim 15 \%$ in 1990 to $\sim 57 \%$ in 2016 , showing that more women are running today than men (www.runningusa.org/2017-us-road-race-trends). Marathon running began as a male-only event in the 1896 Olympic Games (www.sports-reference.com/olympics/ summer/1896/ATH/mens-marathon.html). Women were not allowed to run in the Olympic Marathon until 1984, nearly a century later (18).

However, women began running the $42-\mathrm{km}$ marathon distance 2 decades before 1984 . The first woman to run the Boston Marathon, Roberta Gibb, completed the distance unofficially in 1966 with a time of 03:21:40 h:min:s, ahead of two thirds of all the men. Finally, in 1972, female runners were accepted as official contestants in the Boston Marathon, with Nina Kuscsik leading 5 women across the finish line with a winning time of 03:10:26 h:min:s (18).

Although women have now been competing for more than 4 decades in races such as the Boston Marathon and the New York City Marathon $(2,18)$, very little is known regarding the sex differences in marathon running. In particular, we have little to no knowledge about the trends in sex differences since the 1970s because most studies investigating performance differences examined differences in only the top performances between women and men or used only the top athletes over a short period of time, such as a few years 
or a few decades $(8,9,16)$. An analysis of the change in differences between the sexes in marathon running since women began competing is, however, missing.

When the standing world's best running performances at distances of $100 \mathrm{~m}-200 \mathrm{~km}$ were investigated in 2002 , men were $\sim 12.4 \%$ faster than women (4). When the annual world rankings from 1980 to 1996 for the $1,500 \mathrm{~m}$ and the marathon were analyzed, the time differences between the sexes for marathon running was consistently $\sim 11.2 \%$ between 1980 and 1996 (21). When marathon race times for the top 10 women and men from 1980 to 2010 in the New York City Marathon were analyzed by age group, an increase in the sex ratio was found with increasing age and place. This was explained by the lower number of women competing with increasing age compared with men (8).

Considering the increased participation of women in marathon running (9), knowledge about the sex differences in performance is of great practical importance for coaches and trainers working with marathoners, as well as for those recreational runners training without the supervision of a specialist. As existing information is derived from research conducted mostly on men (17), studying the sex differences would contribute to the development of sex-tailored training programs. And as training programs become even more individualized, information about sex-specific differences in marathon performance might contribute to specialized training programs.

Therefore, the aim of the study was to investigate the trend in differences between the sexes in marathon running for women and men competing in the Boston Marathon since 1972, when the first women officially completed the Boston Marathon (www.baa.org/races/boston-marathon/ boston-marathon-history/boston-marathon-milestones.aspx). Regarding existing findings, we hypothesized that women have reduced the performance gap between themselves and men in the past 45 years of this specific race.

\section{Methods}

\section{Experimental Approach to the Problem}

To test our hypothesis, data on all successful Boston Marathon female and male finishers since 1972, the first race in which female marathoners were allowed, were obtained from the official race website (www.baa.org/ races/boston-marathon.aspx).

\section{Subjects}

The Boston Marathon is the world's oldest annual marathon (www.baa.org/races/boston-marathon/boston-marathonhistory.aspx) (14). To compete in this race, athletes must meet the time standards that correspond to age and sex (www.baa.org/races/boston-marathon/participant-information/ qualifying.aspx). To start in this race, a runner has to be 18 years or older. This study was approved by the Institutional Review Board of Kanton St. Gallen, Switzerland, with a waiver of the requirement for informed consent of the participants as the study involved the analysis of publicly available data.

\section{Procedures}

Data, collected annually from 1972 to 2017 for both women and men, were obtained from the official race website (www. baa.org/races/boston-marathon.aspx). The available information was as follows: the name and surname of the runners, sex, runners' nationality, year of competition, and race times where age was missing. We integrated this data set with other information for the year 2005. From the year 2005, race results were incomplete in the official race website, so we obtained these results from www.marathonguide.com/ results. We edited the data set, correcting for double coding of the same level of categories (i.e., female abbreviated with both "F" and "W," single nationalities with many country codes). Moreover, we removed runners with missing or questionable (unreliable) information on race time. Unfortunately, we did not have the complete list of all runners belonging to the push rim wheelchair division, started in 1975 for men and in 1977 for women. We attempted to exclude this category by eliminating runners with race times faster than the annual top record. To identify observations about a single runner, we defined an id variable with name, surname, sex, nationality, and period of competition, supposing that a single runner could participate at most for 25 years.

\section{Statistical Analyses}

All data are presented as mean values $\pm S D$ s for continuous variables and as number $N(\%)$ for categorical variables. Calendar year was considered as both a discrete value of a continuous variable and as an endpoint of a time-interval categorical variable. In fact, to compare performance by period of time, we grouped each calendar year into 5 classes: 4 periods of 10 calendar years (from 1972 to 2011) and a remaining 6-year period (from 2012 to 2017). We used the following conventions: [year 1, year 2] denoted interval from year 1 (included) to year 2 (excluded) and [year 1, year 2] denoted interval from year 1 (included) to year 2 (included). Performance, or race time, was recorded in the format "hours:minutes:seconds" (h:min:s). The acceptable type I error was set at $p \leq 0.05$. All statistical analyses were performed using the statistical package $\mathrm{R}, \mathrm{R}$ Core Team (2016). $\mathrm{R}$ is a language and environment for statistical computing (R Foundation for Statistical Computing, Vienna, Austria, URL https://www.R-project.org/).

For data visualization, we used a ggplot2 package. We performed a $t$-test to compare the average speed between sexes and by period of time, grouped into 5 classes. Moreover, effects of sex, calendar year, and their interaction were considered through a spline regression model, as a function of the calendar year. Because we have repeated measurements among the runners, we performed a mixed model, with random effects on intercept for each runner. We used Generalized Additive Mixed Models, which are extensions of Generalized Additive Models, allowing for repeated measurements and then for random effects. In a Generalized 
TABLE 1. Participation by sex and period of time.

\begin{tabular}{|c|c|c|c|c|}
\hline Period* & Sex & $\mathrm{N}$ & $\%$ & Range (min-max) \\
\hline 1972, 1982 & $\mathrm{~F}$ & 1,443 & 5.72 & $1.52 \dagger-16.76$ \\
\hline 1972, 1982 & $M$ & 23,777 & 94.28 & $83.24-98.48$ \\
\hline 1982,1992 & $\mathrm{~F}$ & 7,776 & 14.23 & $9.60-18.02$ \\
\hline 1982,1992 & $M$ & 46,857 & 85.77 & $81.98-90.40$ \\
\hline 1992, 2002 & $\mathrm{~F}$ & 34,817 & 27.34 & $19.27-35.90$ \\
\hline 1992, 2002 & M & 92,529 & 72.66 & $64.10-80.73$ \\
\hline 2002,2012 & $\mathrm{~F}$ & 78,026 & 39.53 & $36.63-42.13$ \\
\hline 2002,2012 & $M$ & 119,343 & 60.47 & $57.87-63.37$ \\
\hline 2012,2017 & $\mathrm{~F}$ & 65,936 & 44.16 & $40.17-45.68 \ddagger$ \\
\hline 2012,2017 & $M$ & 83,386 & 55.84 & $54.32-59.83$ \\
\hline
\end{tabular}

*[year 1, year 2): interval from year 1 (included) to year 2 (excluded); [year 1, year 2]: interval from year 1 (included) to year 2 (included).

$\dagger$ The global minimum of female participation occurred in 1975.

$\ddagger$ The global maximum of female participation occurred in 2016.

Additive Model, the response variable depends linearly on unknown smooth functions of some predictor variables. We used $\mathrm{R}$ package gamm4. The model was specified as follows:

$$
\begin{aligned}
& \text { Race } \operatorname{Time}(\mathrm{Y}) \sim[\text { Fixed effects }(\mathrm{X}) \\
& \begin{aligned}
= & \text { Sex }+\mathrm{BS}(\mathrm{YEAR}, \mathrm{df}=\mathrm{k}) \\
& +\mathrm{Sex} \times \mathrm{BS}(\mathrm{YEAR}, \mathrm{df}=\mathrm{k})] \\
& +[\text { Random effects of intercept }=\text { Runners }]
\end{aligned}
\end{aligned}
$$

where BS (YEAR, $d f=k)$ is $k$ a degree of freedom $(\mathrm{df})$, basis splines changing with the calendar year.

We performed 5 different analyses and regression models: 1 for all runners, 1 for the annual top 10 finishers, and 1 for the annual winners, plus 2 additional analyses for the nearelite finishers. We identified 2 groups of near-elite finishers, with 1 for the annual finishers ranked from the 21st to the 100th place and another one for finishers from the 101st to the 200th place. $\mathrm{K}$ was set to 5 for the model of all runners and to 3 for the other groups. Observed values of performance differences between the sexes, in \% by calendar year, were calculated as $100 \times$ (women's mean race time - men's mean race time)/men's mean race time. For fitted values of performance differences, we use the same formula, replacing mean race time with the corresponding fitted value.

\section{Results}

\section{Participation}

Between 1972 and 2017, a total of $n=553,890$ records on 371,250 different finishers were recorded in the race results. Therefore, we often had multiple observations per runner. Overall, the average was 1.49 records per runner, but in fact, only 90,326 (24\%) runners have more than 1 record. These runners participated on average 3 times throughout the period of observation. The maximum number of records was 26 , which meant that a runner participated annually during the past 25 years.

The number of women was 134,725 (36\%), with 187,998 records (34\% of the total observations), and the number of men was $236,525(64 \%)$, with 365,892 (66\%) records. In Table 1, we report participation by sex and period of time. We observed that female participation has increased over the years. The minimum participation occurred in 1975, where women represented only $1.52 \%$ of the total annual runners. The maximum participation was in 2016, where women represented $45.68 \%$ of the total annual runners. Because of the low numbers during the first years, in Figure 1, we focus the analysis on the past 4 decades (from 1978 to 2017), providing details of participation for each calendar year and plotting the male/female ratio (number of males/number of females).

\section{Performance Considering All Finishers}

Overall, a trivial effect of sex on race time was observed $(p<$ 0.001), with men (03:38:42 \pm 00:41:43 h:min:s) being faster than women (04:03:28 \pm 00:38:32 h:min:s) (Table 2). On average, the time difference between the sexes was $10.7 \%$. When we consider overall performance by sex, corrected for repeated measurement (not shown in Table 2), we have 03:40:43 \pm 00:41:52 h:min:s for men and 04:05:08 \pm 00:38:41 h:min:s for women $(p<0.001)$. We have effects of both sex and period of time. We found significant differences in mean performance between men and women for each period of time $(p<0.001)$. It seemed that performance, for both men and women, had gradually worsened. But this was in fact because of the increased participation of both sexes (as shown in Table 1) and then to an increased variability in terms of $(S D$, Table 2). In particular, the worst 


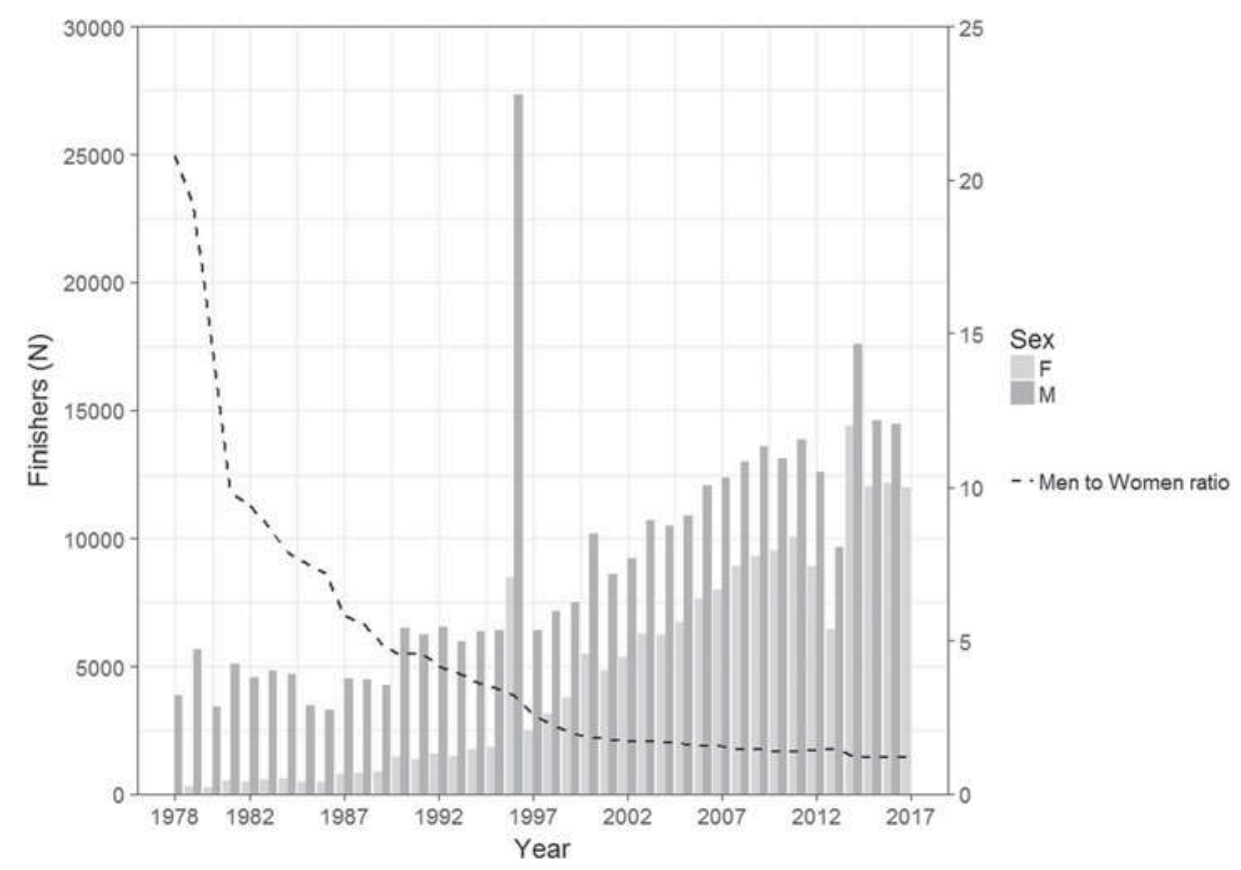

Figure 1. Finishers by sex and calendar year, from 1978 to 2017 , with the men-to-women-ratio.

average performance, for both sexes, occurred in the period 2002-2012, with 04:08:10 \pm 00:36:27 h:min:s for women and 03:48:38 \pm 00:41:36 h:min:s for men.

The fastest average male performance was reached in 1974 (02:30:31 \pm 00:06:25 h:min:s) and the fastest average female performance in 1975 (03:11:46 \pm 00:13:03 h:min:s). The slowest average performance for both sexes was reached in 2004 (women: 04:36:02 \pm 00:39:38 h:min:s, men; 04:16:16 \pm 00:46:53 h:min:s).

However, because the number of records was low in the beginning years, we plotted points showing the details of mean performance by calendar year from 1978 to 2017 (Figure 2A). Moreover, in Figure 2A, we show the fitted curve, by sex, from the generalized additive mixed model described above and whose details are reported in the Appendix (see Table A.1, http://links.lww.com/JSCR/A102). The fastest average male performance after 1978 was reached in 1981 (02:58:56 \pm 00:19:42 h:min:s) and the fastest average female performance in 1980 (03:14:32 \pm 00:13:50 h:min:s). In Figure 3, we show the performance differences between the sexes in \% for each calendar year from 1978 to 2017.

For all finishers, points represented observed mean values; lines were fitted values, as in Figure 2A. Differences in time between the sexes increased from a minimum of $-5.2 \%$ to a maximum of $+11.8 \%$. The minimum was reached in 2012 , the only year in which women (03:36:45 \pm 00:34:49 h:min:s) were, on average, faster than men $(03: 48: 46 \pm 00: 30: 35 \mathrm{~h}$ :min:s). The maximum occurred in 1983, with 03:21:03 \pm 00:16:01 h:min:s for women and 02:59:51 \pm 00:20:14 $\mathrm{h}: \mathrm{min}: \mathrm{s}$ for men. The differences decreased but not monotonically. From 1992 to 2002, the difference increased from 8.8 to $10.7 \%$, then decreased again to $8.7 \%$ in 2017 .

\section{Performance Considering the Annual Ten Fastest}

A major effect of sex on race time was observed $(p<$ $0.001)$, with men $(02: 13: 30 \pm 00: 04: 08 \mathrm{~h}: \mathrm{min}: \mathrm{s})$ being faster than women (02:37:42 \pm 00:17:58 h:min:s) (Table 2). The average difference was $18.3 \%$. We also found significant differences in mean performance between men and women for each period of time $(p<0.001)$. On average, the best period, in terms of performance, was 1992-2002 for both sexes, with 02:29:44 \pm 00:03:21 h:min:s for women and 02:11:13 \pm 00:01:55 h:min:s for men. In comparison, the slowest average men's performance took place in 1976 (02:24:11 \pm 00:02:25 h:min:s) and the slowest average women's performance in 1972 (03:59:2 \pm 00:43:21 h:min:s). In Figure 2B, plotted points show the details of mean performance by calendar year from 1978 onward.

The fastest average men's performance was reached in 2011, with 02:05:10 \pm 00:01:29 h:min:s, and the fastest average women's performance was in 2014, with 02:22:05 \pm 00:01:30 h:min:s. In comparison, the slowest average men's performance took place in 1985 (02:21:50 \pm 00:03:17 $\mathrm{h}: \min : \mathrm{s})$ and the slowest average women's performance in 1978 (02:49:55 \pm 00:03:23 h:min:s). Figure 2B shows the

4 Journal of Strength and Conditioning Research 
fitted curve by sex from the mixed model described above, and we report the details in the Appendix (see Table A.1, http://links.lww.com/JSCR/A102). We found 918 observations for 725 runners. In Figure 3, we show the performance differences between the sexes in \%, focusing the analysis from 1978 onward. The differences increased from a minimum of $8.9 \%$ to a maximum of $28.4 \%$. The minimum was reached in 2014 , with 02 : 22:05 \pm 00:01:30 h:min:s for women and 02:10:27 \pm 00: 01:28 h:min:s for men. The maximum occurred in 1978, with 02:49:55 \pm 00:03:23 h:min:s for women and 02:12: $23 \pm$ 00:01:49 h:min:s for men. The difference decreased quickly during the first 10 years, then decreased more slowly, then increased, but in the past 5 years decreased again, although not monotonically. In 2017, the performance difference was at $11.5 \%$.

\section{Performance Considering the Annual Winners}

All of the elite male runners (02:10:24 \pm 00:03:05 $\mathrm{h}: \mathrm{min}: \mathrm{s})$ ran faster than the elite female runners (02:30:43 \pm 00:11:05 h:min:s) $(p<0.001)$ (Table 2). The average difference was $15.5 \%$. The best period, in terms of average performance, was 1992-2002 for women (02:24:39 \pm 00:01:42 h:min:s) and 2002-2012 for men (02:08:50 \pm 00:03:08 h:min:s). In Figure 2C, plotted points show the details of mean performance by calendar year from 1978 onward. The fastest men's performance was reached in 2011, with 02:03:02, and the fastest women performance took place in 2014, with 02:19:59 h:min:s. In comparison, the slowest male performance was reached in 2012, with 2:12:40 h:min:s by Wesley Korir, and the slowest female performance took place in 2013 with 2:26:25 h:min:s by Rita Jeptoo. In Figure $2 \mathrm{C}$, we show the fitted curve by sex from the mixed model described above and report the details in the Appendix (see Table A.1, http://links.lww.com/ JSCR/A102). We worked with 92 observations for 76 runners. In Figure 3, we show the performance differences between men and women in \%, focusing the analysis from 1978 onward. Differences increased from a minimum of $8.8 \%$ to a maximum of $27.8 \%$. The minimum was reached in 2014, with the women's record of 02:19:59 h:min:s and the men's record of 02:08:37 h:min:s. The maximum occurred in 2013, with 02:46:37 h:min:s for the women's record compared with 02:10:22 h:min:s for the men's record. The difference decreased nonmonotonically over the years and decreased less quickly than it did among the top 10 finishers. In 2013, the performance difference was 1.7 times the value of 2012. In 2017, the difference was $9.4 \%$.

\section{Performance Considering the Near-Elite Finishers From} the 21st to the 100th Place

In general, near-elite male runners (02:29:17 \pm 00:06:31 h:min:s) were faster than near-elite female runners (03:01:54 \pm 00:10:09 h:min:s $)(p<0.001)$, with an 

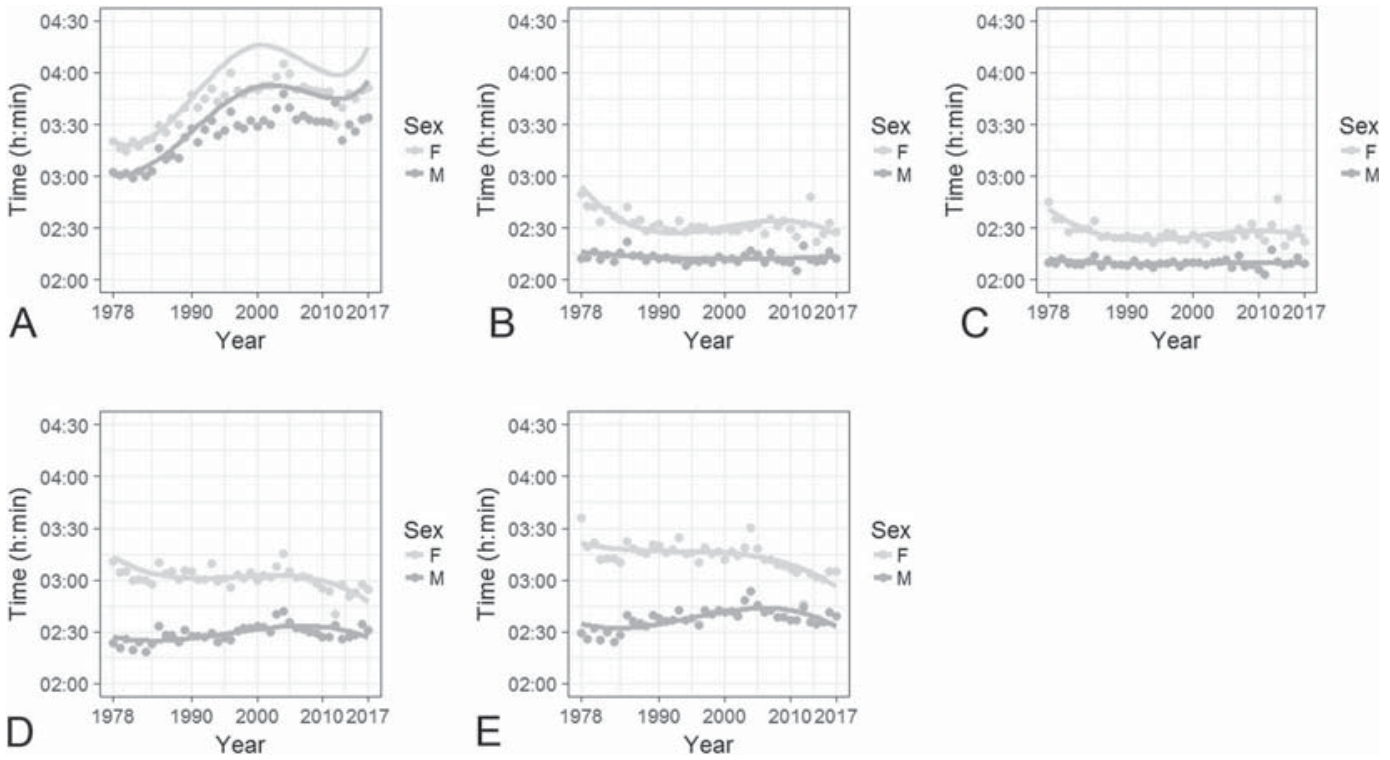

Figure 2. Performance by sex and calendar year from 1978 to 2017 , of all finishers (A), top 10 (B), winners (C), near-elite athletes from the 21 st to the 100 th place (D), and near-elite athletes from the 101st to the 200th place (E). Points are average of time race. Lines are fitted curves.

average difference of $23.4 \%$, not shown in tables. In Figure 2D, plotted points show the details of mean performance by calendar year from 1978 onward. The fastest average men's performance was reached in 1983 at
02:18:09 \pm 00:01:53 h:min:s, and the fastest average women's performance took place in 2012 at 02:40:13 \pm 00:02:16 h:min:s. In comparison, the slowest performance was reached in 2004 for both sexes, with men at 02:42:12 \pm 00:04:18

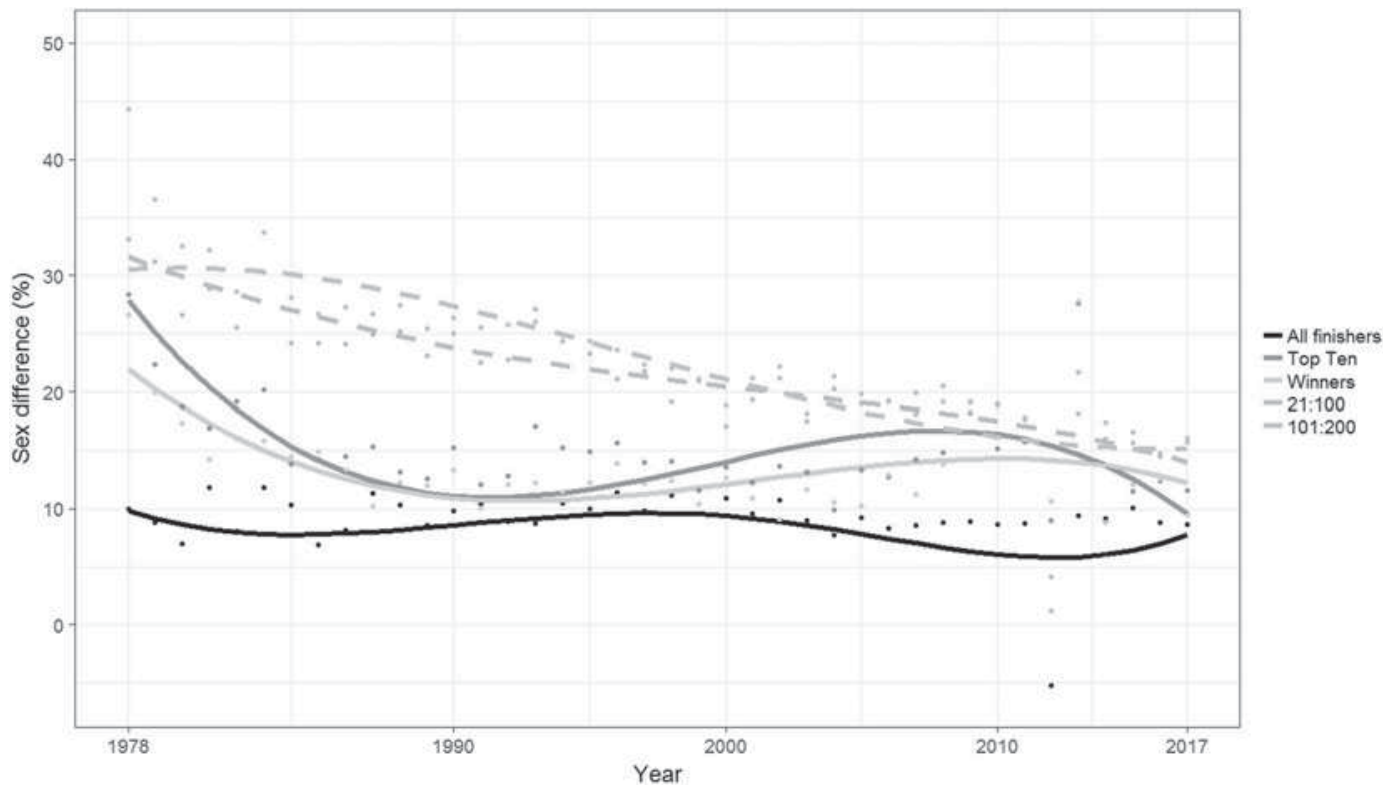

Figure 3. Sex differences, in \% by calendar year, from 1978 to 2017, and subgroups: all finishers, top 10, and winners. Points are observed mean differences. Lines are fitted mean differences.

6 Journal of Strength and Conditioning Research 
h:min:s and women at 03:15:05 \pm 00:07:03 h:min:s. Figure 2D shows the fitted curve by sex from the mixed model described above, but the details were not reported. We worked with 6,988 records for 5,739 runners. In Figure 3, we show the performance differences between the sexes in \%, focusing the analysis from 1978 onward. Differences increased from a minimum of $4.1 \%$ to a maximum of $33.1 \%$. The minimum was reached in 2012, with the women's record of 02:40:13 \pm 00:02:16 h:min:s and the men's record of 02:33:52 \pm 00:04:28 h:min:s. The maximum occurred in 1978, with 03:10:55 \pm 00:06:41 h:min:s for the women's record compared with 02:23:25 \pm 00:02:41 h:min:s for the men's record. The differences decreased over the years.

\section{Performance Considering the Near-Elite Finishers From the 101st to the 200th Place}

In general, near-elite male runners (02:37:57 \pm 00:06:25 h:min:s) were faster than near-elite female runners (03:13:44 \pm 00:08:54 h:min:s) $(p<0.001)$, with an average difference of 23.9\%, not shown in tables. In Figure 2E, plotted points show the details of mean performance by calendar year from 1978 onward. The fastest men's performance was reached in 1983, with 02:24:09 \pm 00:01:24 h:min:s, and the fastest women's performance took place in 2012 with 02:46:10 \pm 00:01:23 h:min:s. In comparison, the slowest average men's performance was reached in 2004, with 02:53:09 \pm 00:02:17 h:min:s, and the slowest women's performance took place in 1978, with 03:35:48 \pm 00:09:43 h:min:s. Figure $2 \mathrm{E}$ shows the fitted curve by sex from the mixed model described above, but the details were not reported. We found 8,487 observations for 7,352 runners. In Figure 3, we show the performance differences between the sexes in \%, focusing the analysis from 1978 onward. Differences increased from a minimum of $1.2 \%$ to a maximum of $44.3 \%$. The minimum was reached in 2012, with the women's record of 02:46:10 \pm 00:01:23 h:min:s and the men's record of 02:44:10 \pm 00:02:06 h:min:s. The maximum occurred in 1978, with 03:35:48 \pm 00:09:43 h:min:s for the women's record compared with 02:29:30 \pm 00:01:23 $\mathrm{h}: \mathrm{min}: \mathrm{s}$ for the men's record. The differences decreased over the years.

\section{Discussion}

We investigated the trend over time in performance difference between the sexes in marathon running for women and men competing in the Boston Marathon since 1972, when the first women officially competed in the race. We hypothesized that women would reduce the performance gap to men in the past 45 years of this race. The most important findings were that (a) the percentage of female participation increased from $\sim 1.5 \%$ in 1975 to $\sim 45.7 \%$ in 2016, and (b) the performance difference between the sexes decreased over the years, depending on whether all, the annual top 10 , the annual winners, or the near-elite finishers were considered. There was a nonlinear trend in perfor- mance difference, especially when all finishers, the top 10 , and the winners were considered, whereas the performance difference decreased rather linearly when the near-elite finishers were considered. It should be highlighted that both these findings were novel as no previous study had ever quantified participation rates or performance differences using all Boston Marathon races since women participated for the first time.

We found an increase in number of both female and male finishers, in which the percentage of female participation increased from $\sim 1.5 \%$ in 1975 to $\sim 45.7 \%$ in 2016 . This increase in overall finishers is most likely due to the increase in the number of female marathoners when they were allowed to participate in marathons, the increase in the number of older marathoners, and the "running boom" that hit the United States from the late 1970s onward $(2,16)$. For example, the number of marathons increased in the United States between 1968 and 1976 by $\sim 300 \%$ (15). Although anecdotic reports exist describing female participation in marathon and ultra-marathon races before $\sim 1970$ (12), the first women officially competed in the Boston Marathon in 1972 (2). The "running boom" might be explained by the fact the women were allowed to run in marathons at the beginning of the seventies and at the beginning of large city marathons such as the "New York City Marathon" (www. runnersworld.com/running-times-info/how-the-runningboom-began).

The participation of women in running is an important aspect regarding the difference in running performance between men and women (16). Generally, more men than women compete in running races such as a marathon (15), and men run faster than women (5). An explanation for the change in performance difference over time in the Boston Marathon is the change in female participation over time. When we consider the trend in female and male participation, the percentage of men continuously decreased, whereas it increased for women. Nowadays, $\sim 46 \%$ of all marathon runners are women. In 1996, we see a very high number of finishers. In that year, the historic 100th running of the Boston Marathon attracted 38,708 entrants with 36,748 starters and had 35,868 official finishers (35,801 considered in our study). It stood as the largest field of finishers in the history of the sport until 2004 (www.baa.org/races/boston-marathon/ boston-marathon-history/boston-marathon-milestones.aspx).

The fastest performances were achieved in different periods of time, depending on whether all women and men, the annual 10 fastest, or the annual fastest were considered. When all female and male finishers were considered, performance for both women and men decreased. The fastest performance for women was found in 1975 and for men in 1974, whereas the slowest performance was found in 2004 for both women and men. When we consider a period of time, the weakest performance occurred in the period 2002-2012 for both women and men. These changes in performance were due to an increased 
participation of both women and men over the years and so because of an increased variability. It has been shown that more and more master runners have started to compete in marathons (13), and currently, runners aged up to $\sim 90$ years also compete in marathons, as well as large numbers of recreational runners (1).

Different results were found when we considered the annual 10 fastest and the annual winners. For the annual 10 fastest, the best performances for both women and men were found in the period 1992-2002, therefore, 1 decade earlier compared with all finishers. In contrast to the results for all finishers, the best results for the annual 10 fastest men were in 2011 and the fastest women in 2014, whereas the worst results for the annual 10 fastest men were in 1976 and women in 1972. This opposite trend compared with all finishers was most likely due to the low number of female participants in the early seventies. For the annual winners, the best performances were achieved in the period 19922002 for women, and 1 decade later, in 2002-2012 for men. The fastest male performance was reached in 2011 and the fastest female performance in 2014.

Improvements in marathon race times among elite runners in the past decades might be explained by the increased participation of East African runners in large city marathons. It has been reported for city marathons held in Switzerland that the fastest race times were achieved by female and male runners from Kenya and Ethiopia (11). East African runners from Kenya and Ethiopia were also the fastest for races in the World Marathon Majors (i.e., Boston, Berlin, Chicago, and New York), (10).

Changes in performance over the years for the Boston Marathon have also been investigated by Zavorsky et al. (21) and Maffetone et al. (14). They analyzed, however, considerably shorter periods of time. Although Zavorsky et al. (21) analyzed data from 2001 to 2016, Maffetone et al. (14) analyzed the period from 2005 to 2014. Zavorsky et al. (21) analyzed the decrease in marathon performance with increasing age and found that female winners of each age group demonstrated a 27 -second greater decline per year compared with male winners of each age group. Maffetone et al. (14) analyzed race times of the 10 male and 10 female finishers in Boston Marathon and other World Marathon Majors races and found that race times were slower in the Boston Marathon compared with the other races.

The performance differences between men and women changed over the years, not depending on whether all women and men, the annual 10 fastest, or the annual fastest were considered. Overall, women reduced the performance gap to men. The decrease in performance difference between the sexes might be explained by the increase in female participation between 1972 and 2017. More women compete now, and also faster women are in the field (4).

When all female and male finishers were considered, the highest performance difference $(\sim 45.1 \%)$ was achieved in 1972 , whereas in 2012 , women were $\sim 5.2 \%$ faster than men. The difference decreased quickly in the first 5 years (1972-1977), but then less quickly and nonlinearly. Between 1992 and 2002, the performance difference increased from $\sim 8.8 \%$ to $\sim 10.7 \%$, then decreased again in 2017 to $\sim 8.7 \%$. Overall, the performance difference was $\sim 10.7 \%$ when all women and men were considered. An explanation for the superior female performance in 2012 could be the weather conditions. In 2012, the temperature reached $75^{\circ} \mathrm{F}\left(23.9^{\circ} \mathrm{C}\right)$ by the start of the women's elite field (9:30 AM), with a high temperature of $89^{\circ} \mathrm{F}\left(31.7^{\circ} \mathrm{C}\right)$ reported in Framingham $(10 \mathrm{~K}$ mark) by midday (www.baa.org/races/boston-marathon/ boston-marathon-history/weather-conditions.aspx).

For the annual 10 fastest runners, the highest performance difference $(\sim 72.5 \%)$ occurred in 1972 , whereas the lowest $(\sim 8.9 \%)$ was found in 2014. In contrast to the results for all finishers, the average difference was $\sim 18.3 \%$. Similarly to the results for all finishers, the difference decreased quickly in the first 10 years, then decreased more slowly to achieve $\sim 11.5 \%$ in 2017. For the annual fastest runners, the highest performance difference $(\sim 40.4 \%)$ was found in 1972 and the lowest $(\sim 8.8 \%)$ in 2014 . Overall, the performance difference for the annual winners was $\sim 15.5 \%$. The difference decreased nonmonotonically and less quickly over the years for the winners than did it for the annual 10 fastest. In 2013, there was a very high difference value of $\sim 27.8 \%$, which decreased to $\sim 9.4 \%$ in 2017 .

We found a performance difference of $\sim 10.7 \%$ when all women and men were considered between 1972 and 2017. When the annual 10 fastest and the annual winners were considered, however, the average performance difference increased to $\sim 18.3 \%$ and $\sim 15.5 \%$, respectively. An explanation of the discrepancy among the methodological approaches (i.e., whether all or top 10 runners were considered) might be the rates of participation. When all runners are considered, it is assumed that, since fewer women than men participate, women finishers might be more selective ("competitive") than men, and thus more able to reduce the gap between the sexes. On the contrary, when the top 10 are considered in the light of the total number of women and men, the top 10 women consist of a larger percentage of the total number of women than the top 10 men do, respectively. That is, the 10 men are more selective ("competitive") and, thus, increase the difference to women.

Regarding Figure 3, there was a nonlinear trend in performance difference when all finishers, the top 10 , and the winners were considered, whereas the performance difference decreased rather linearly when the near-elite finishers were considered. This trend is well explained by the trend in performance in the corresponding groups (Figure 2). However, the rather linear decrease in performance difference among the near-elite finishers might be explained by the increased density of the elite runners.

A performance difference of $\sim 11 \%$ corresponds well with the findings of Hunter et al. (7). These authors 
analyzed running times of the first 5 placed male and female runners who competed in the 7 marathons of the World Marathon Majors Series. And similar to our findings, in their analysis, the difference in performance between elite male and female marathon runners varied over the years. It is very likely that the difference in running performance will remain fairly constant because of the biological differences between men and women that give men an advantage in distance running (19). Running times for women have now reached a plateau similar to that observed for men at comparative performance milestones in the marathon. The remaining gaps in performance seem biological in origin (3).

However, the performance difference of $\sim 11 \%$ between women and men in marathon running is only valid when all women and men are compared. The fastest women increased the distance to the fastest men to $\sim 15 \%$. Although we have data for men covering more than 100 years, we have data for women covering only about 50 years. In the early years of the Boston Marathon, men had to run on muddy roads, with bad shoes, bad nutrition, no fluids, and little training. These days, women and men train similarly and have appropriate equipment for marathon running. Furthermore, race times are measured electronically when the runner passes the start and the finish line. Future studies need to investigate other marathon races to confirm these findings for the Boston Marathon.

The findings of the present study are limited by the specific characteristics of the race in terms of environmental conditions (e.g., topography, temperature) and participation (e.g., qualifying criteria). Thus, they should be generalized with caution to other marathon races. For example, in 2004, the weather was hot with a temperature of $25^{\circ} \mathrm{C}$ at the start and increasing to $29^{\circ} \mathrm{C}$, with humidity at $32 \%$. This seemed to have influenced both sexes and resulted in the worst performance of all finishers and near-elite runners. In 2012, it was very hot with temperature of $33^{\circ} \mathrm{C}$ and $46 \%$ humidity. This seemed to have influenced the men's performance (annual winners) more than the women's performance (www.baa.org/races/bostonmarathon/boston-marathon-history/weather-conditions. aspx). Moreover, we had no information about age, and we could not exactly identify repeated measurements among runners, although we could reasonably suppose that 2 records belonged to the same runner if they had in common both name, surname, sex, country, and participation within the same period of time. A limitation is that we must be aware that not all official finishers in the early years were recorded when compared with the number of participants (www.bostonmarathonmediaguide.com/qualification/ participation/). For example, the number of finishers in 1974 seems too low, which can easily be seen in Figure 1 in the men-to-women ratio. According to the race director, "The only results we have are those recorded by the athletics offi- cials, who often went home before the last finishers completed the course" (personal communication). In later years, the number of finishers corresponds well with the number of participants. However, in 2012, women outscored men on average, which is unusual but could be explained by the fact that the men did not cope with the heat as well as the women, did and thus, many more men slowed dramatically. It has been shown in the Stockholm Marathon that effects of warm weather were less evident for women than men in marathon running, which was probably partly due to women's' larger ratio of surface area to body mass and slower running speed (20). Therefore, the result for 1974 with the fastest average male performance must be considered with caution because, in that year, it is likely that not all male finishers were officially recorded. We also have to mention that the Boston Marathon is the only large city marathon in the world with qualifying times (www.baa.org/races/boston-marathon/participantinformation/qualifying/history-of-qualifying-standards. aspx), and the qualifying standards could favor 1 sex or age group over the other. Qualifying standards for the Boston Marathon have been used since 1970 for men and since 1972 for female runners. To qualify for the Boston Marathon, athletes must meet the time standards that correspond to age and sex (www.baa.org/races/boston-marathon/participantinformation/qualifying.aspx). It is important to know that the qualifying standards have changed since 1970 (www. baa.org/races/boston-marathon/participant-information/ qualifying/history-of-qualifying-standards.aspx). It is generally regarded as easier for women than men to qualify for the Boston Marathon, which may change the results. The male standards are substantially closer to the men's world record than the female standards are to the female world record. Furthermore, the standards are also considerably easier for older runners than for younger runners. And, for the past decade or more, more than $10 \%$ of the runners did not achieve the qualifying standards. They became eligible to run because they raised money for charity (www. runnersworld.com/boston-marathon/tension-between-bostonscharity-runners-and-qualifiers-disappears-by-race-day). Therefore, the change in the qualifying process over the years might have had an influence on the performance differences between the sexes. A further point is the prize money in the Boston Marathon. Prize money has been offered in the Boston Marathon since 1986 (http://womensrunning.competitor.com/ 2018/04/boston2018/history-of-boston-marathon_88768). Currently, the top 15 women and men overall and the top 5 runners in each age group receive it (www.baa.org/races/ boston-marathon/event-information/prize-money-and-awards. aspx). Two years after offering the prize money, Kenya's Ibrahim Hussein finished 1 second ahead of Tanzania's Juma Ikangaa and became the first African to win the Boston Marathon (www.baa.org/races/boston-marathon/bostonmarathon-history/boston-marathon-milestones.aspx). Since then, East African runners have dominated marathon running, and they compete for the money (www.newyorker. 
com/news/sporting-scene/running-for-money). This might have had a considerable influence on the participation and performance of the top female and male runners. The recruitment of elite runners is generally kept secret, and the performances of the annual top 10 and the annual winners for the Boston Marathon really fail to provide insights on the quality of the best male and female runners. There could be all kinds of recruitment biases, and the biases probably change over time. A further, smaller point is the fact that, for most years, women ran with the men, thus they had pacers all along the course. For about the past 10 years, women have run alone, ahead of the men. They do not have pacers. This might have a small overall effect on performance differences over the decades. In 2013 was the bombing attack (www.history.com/topics/boston-marathon-bombings), which seemed to have influenced the performance of the female annual winners. On the other hand, the strength of the study was that it analyzed the trends in performance and participation in one of the most popular marathon races worldwide, considering all finishers (> half million) throughout its history. To the best of our knowledge, this was the first study to analyze trends in participation and performance in the Boston Marathon using all available data since the first year of participation by women, and given the popularity of this race, the findings would be of great practical importance for strength and conditioning coaches (see "Practical application" section below).

\section{Practical Applications}

The Boston Marathon has been held since 1897, with women first officially allowed to run in 1972. Although the considered database might not be reliable regarding all finishers in the seventies, men were $\sim 10.7 \%$ faster than women between 1972 and 2017. The fastest annual men (top 10 and winners) increased the gap to women on average to $\sim 18.3 \%$ and $\sim 15.5 \%$, respectively. Furthermore, the performance difference of $\sim 15 \%$ for the fastest women and men needs confirmation through studies on other large city marathons such as the New York City Marathon. The performance differences of East African marathoners competing in the largest city marathons in the past decades need to be especially investigated. Since marathon running continues to increase in popularity, the findings are of great interest for strength and conditioning coaches working with marathoners, as well as for scientists focusing on differences in male and female performance. Strength and conditioning coaches usually train marathon runners in small groups that may include both sexes. Based on the results of the present study, coaches should consider sex in setting optimal training goals and prescribing exercise to marathon runners, as well as considering performance level, i.e., the sex differences should be considered more as performance level increases. In addition, strength and conditioning coaches should be concerned about the increased rates of partici- pation, which imply that the profile of marathon runners has gradually become more recreational and less competitive. Findings from other sports have suggested that elite athletes are more motivated in performance than recreational athletes (18). Furthermore, recreational marathon runners present different physiological and psychological characteristics than their competitive counterparts $(6,8)$. As the rates of participation change throughout years, it is of great practical value for strength and conditioning coaches to be informed and apply this knowledge into daily training practice.

\section{ACKNowledgments}

The help of Amby Burfoot through his constructive criticism and comments is gratefully acknowledged. The authors also thank Patricia Villiger for her contribution to the English editing.

\section{REFERENCES}

1. Ahmadyar, B, Rosemann, T, Rust, CA, and Knechtle, B. Improved race times in marathoners older than 75 years in the last 25 years in the world's largest marathons. Chin J Physiol 59: 139-147, 2016.

2. Burfoot, A. The history of the marathon: 1976-present. Sports Med 37: 284-287, 2007.

3. Cheuvront, SN, Carter, R, Deruisseau, KC, and Moffatt, RJ. Running performance differences between men and women: An update. Sports Med 35: 1017-1024, 2005.

4. Cushman, DM, Markert, M, and Rho, M. Performance trends in large $10-\mathrm{km}$ road running races in the United States. J Strength Cond Res 28: 892-901, 2014.

5. Deaner, RO. Distance running as an ideal domain for showing a sex difference in competitiveness. Arch Sex Behav 42: 413-428, 2013.

6. Gordon, D, Wightman, S, Basevitch, I, Johnstone, J, Espejo-Sanchez, $\mathrm{C}$, Beckford, C, et al. Physiological and training characteristics of recreational marathon runners. Open Access J Sports Med 8: 231-241, 2017.

7. Hunter, SK and Stevens, AA. Sex differences in marathon running with advanced age: Physiology or participation? Med Sci Sports Exerc 45: 148-156, 2013.

8. Jaenes Sánchez, JC. Hardy personality in sports. Revista Andaluza de Medicina Del Deporte 2: 98-101, 2009.

9. Joyner, MJ. Physiological limits to endurance exercise performance: Influence of sex. J Physiol 595: 2949-2954, 2017.

10. Knechtle, B, Aschmann, A, Onywera, V, Nikolaidis, PT, Rosemann, $\mathrm{T}$, and Rust, CA. Performance and age of African and non-African runners in world marathon majors races 2000-2014. J Sports Sci 35: 1012-1024, 2017.

11. Knechtle, B, Nikolaidis, PT, Onywera, VO, Zingg, MA, Rosemann, $\mathrm{T}$, and Rust, CA. Male and female Ethiopian and Kenyan runners are the fastest and the youngest in both half and full marathon. SpringerPlus 5: 223, 2016.

12. Kuscsik, N. The history of women's participation in the marathon. Ann N Y Acad Sci 301: 862-876, 1977.

13. Lepers, $\mathrm{R}$ and Cattagni, $\mathrm{T}$. Do older athletes reach limits in their performance during marathon running? Age 34: 773-781, 2012.

14. Maffetone, PB, Malcata, R, Rivera, I, and Laursen, PB. The boston marathon versus the world marathon majors. PLoS One 12: e0184024, 2017. 
15. Maron, MB and Horvath, SM. The marathon: A history and review of the literature. Med Sci Sports Exerc 10: 137-150, 1978.

16. Pate, RR and O'Neill, JR. American women in the marathon. Sports Med 37: 294-298, 2007.

17. Sjodin, B and Svedenhag, J. Applied physiology of marathon running. Sports Med 2: 83-99, 1985.

18. Šmela, P, Pacesova, P, Kraček, S, and Hájovský, D. Performance motivation of elite athletes, recreational athletes and non-athletes. Acta Physica 57: 125-133, 2017.
19. Sparling, PB, O’Donnell, EM, and Snow, TK. The gender difference in distance running performance has plateaued: An analysis of world rankings from 1980 to 1996. Med Sci Sports Exerc 30: 1725-1729, 1998.

20. Vihma, T. Effects of weather on the performance of marathon runners. Int J Biometeorol 54: 297-306, 2010.

21. Zavorsky, GS, Tomko, KA, and Smoliga, JM. Declines in marathon performance: Sex differences in elite and recreational athletes. PLoS One 12: e0172121, 2017. 